\title{
Price Risk for Coal Liquefaction in Moderate Scale Development
}

F Varayesi ${ }^{1}$, F N Nazar ${ }^{1}$

'Department of Petroleum Engineering, School of Engineering and Technology, Tanri Abeng University, Jl. Swadarma Raya No.58, South Jakarta, Jakarta, Indonesia

*Corresponding Author: fidva.varavesi@tau.ac.id

\begin{tabular}{l}
\hline \hline Article History: \\
\hline Received: July 29, 2019 \\
Receive in Revised Form: September 20, 2019 \\
Accepted: October 20, 2019
\end{tabular}

Keywords:

Price risk, Liquefaction, Syngas, Coal.

\begin{abstract}
Price risk assessment is conducted by analyzing the value of volatility and ROI. To estimate the energy that results from liquefaction processes we conduct comparison of water content based on temperatures of low temperature fischer tropsch. The temperature range is from $200-250 \mathrm{deg} \mathrm{C}$ and the pressure range is from 20 - 50 bara. The method to calculate energy from liqueafaction process is linde hampson. Each coal type has a different HHV value depending on its composistion. Syngas price prediction in the future is done using the black scholes method, while the value of water content is determined using the Bukacek and khled methods. The method used to determine price risk is to look at the effect of water content on COPat values, then compare risks based on the value of $\$$ space that is affected by COPat values. Risks are also compared through the price volatility and ROI parameters and analyze the NPV value of each cola type to see the comparability of the project based on the value of water content.
\end{abstract}

\section{INTRODUCTION}

Price risk assessment is conducted by analyzing the value of volatility and ROI. To estimate the energy that results from liquefaction processes we conduct comparison of water content based on temperatures of low temperature fischer tropsch. The temperature range is from $200-250 \mathrm{degC}$ and the pressure range is from $20-50$ bara. The method to calculate energy from liqueafaction process is linde hampson. Each coal type has a different HHV value depending on its composition. Syngas price prediction in the future is done using the black scholes method, while the value of water content is determined using the Bukacek and khled methods

The method used to determine price risk is to look at the effect of water content on COPat values, then compare risks based on the value of $\$$ space that is affected by COPat values. Risks are also compared through the price volatility and ROI parameters and analyze the NPV value of each cola type to see the comparability of the project based on the value of water content.

When the latent heat of vaporization is extracted from the fuel products, causing the water to become liuid, the fuel energy density is identify as $\mathrm{HHV}$, and when the equipment used allows thw water to remain in the vapoe state, the energy density is identified as LHV (Petchers, 2003).

Block diagram of liquefaction plant, liquefaction plant compose 3 major processes including pretreatment section, liquefaction section and post treatment section (Kandiyoti et al., 2006). Making liquid from coal need to add hydrogen or reject carbon (Robinson, 2009). Direct coal liquefaction commonly refers to catalytic hydrogenation of coal in a recycled oil solvent at high pressures with catalyst (Harris \& Roberts, 2013).

The fischer topsch process is gas to liquid polymerization technique that turns the carbon sources into hydrocarbon chains through the hydrogenation of carbon monoxide by means of metal catalyst. The feedstock is typically coal or natural gas though more exotic possibilities such as removing $\mathrm{CO}_{2}$ from the atmosphere or ocean has been considered. (Hubbard, 2015) even without the synthesis fuel being carbon neutral, fischer tropsch is predicted to play a big role in the future of liquid fuels. 
(Pratt, 2012) small scale reactors (20bbl/day) for synthetic liquid fuels production are an emerging development area may be enable biomass mobile to liquid plants, suited for demand liquid fuel production.the design such as oil refinery is a significant departure from large scale. According (Yilmaz, Cetin, Ozturkmen, \& Kanoglu, 2019) cryogenic is the science that involves study of very low temperature usually obtained by using liquefaction gas such as liquid nitrogen or liquid helium.

The optimization of the performance of a single stage Linde-Hampson refrigerator (LHR) operating with six different binary refrigerants with ozone depletion potensials of zero was conducted using a new approach at the temperature level of -60degC (Wang, Cui, Sun, Chen, \& Chen, 2010). The results of optimization of pressure levels indicate that the optimum low pressure value for coefficients of performance (COP) is achieved when the minimum temperature differences occur at both the hoit and the cold ends of the recuperator at a specified composition and pressure ratio. On the other hand, the binary refrigerant pssess the advantage of easy handling in the design, production and maintenance of the refrigerator, especially easy partial recharging after the leak of some refrigerant, compared to the multi component refrigerant.

\section{METHOD}

$\mathrm{LHV}=\mathrm{HHV}(1-\mathrm{M})-2.447 \mathrm{M}$

$\mathrm{HHVd}=0.35 \mathrm{Xc}+1.18 \mathrm{XH}+0.10 \mathrm{Xs}-0.02 \mathrm{XN}-0.10 \mathrm{Xo}-0.02 \mathrm{Xash}$

Based on Yilmaz et al,2019, Copact is the number of coefficients obtained from the comparison of the number $\mathrm{q}$ with Win which is affected by the enthalpy parameter

$$
\begin{aligned}
& C O P_{\text {act }}=\frac{q_{1}}{W_{\text {in }}}=\frac{h_{1}-h_{2}}{h_{2}-h_{1}-T_{1}\left(S_{2}-S_{1}\right)} \\
& \eta_{I I}=\frac{w_{\text {rev }}}{W_{\text {act }}}=\frac{h_{6}-h_{1}-T_{1}\left(S_{6}-S_{1}\right)}{\left(\frac{1}{y}\right)\left[h_{2}-h_{1}-T_{1}\left(S_{2}-S_{1}\right)\right]} \\
& \$ \text { space }=h x \frac{\text { Qmax }}{\text { COP }} x \$ \text { unit } \\
& \$ \text { space }=\text { cost of space heating } \\
& \mathrm{h}=\text { number of hours operated per year } \\
& \text { COP }=\text { coefficient of performance } \\
& \text { Qmax }=\text { maximum heat load }(\mathrm{kW}) \\
& \$ \text { space }=\text { unit cost of electricity }(\$ / \text { year) } \\
& \text { Return on sales }=\frac{\text { Profit }}{\text { Net Sales }} x 100 \\
& \text { Arithmetic Price Change }=\frac{P 2-P 1}{P 1} x 100 \\
& \text { Logarithmic Price Change }=\ln \frac{P 2}{P 1} x 100 \\
& \text { ROI }=\frac{\text { Profit }}{\text { Investment cost }} x 100
\end{aligned}
$$

The standard deviation value can be influenced by the values of $\mathrm{x}$ and xiPi which describe the possibility of losses occurring and the expected value and the amount of data analyzed to determine the risk value.

The calculation of $\$$ space heating aims to find out the price of the heat capacity produced by the linde hampson system, the price of space heating is determined by the COP parameters namely the coefficient of performance efficiency of the Linde Hampson system. In this research, the calculation of heat in the temperature range of $200-$ $250 \mathrm{deg} \mathrm{C}$ is performed. The research method is done by calculating the value of water content based on the Bukacek and Khaled method, but the bukacek approach not in accordance with the standard water content values, from these two methods the difference in HHVd values obtained form the composition value of each coal type.

WH2O (water content) is influenced by the value of the mole fraction (y) of the values of C, H,O and $\mathrm{S}$ in each of the four coal type. The calculation is based on the temperature and pressure values for each type coal. The temperature and pressure values affect the amount of water content. Then form the value of water content, affect the enthalpy value in the process of calculating the energy of liquefaction that is influenced by LHV and HHVd, the risk is seen from the loss of enthalpy in the difference in the value of water content.

Liquefaction in coal aims to change the coal phase which was previously a solid into a liquid phase. In the liquefaction process with moderate scalar stages. In this capacity, an economic study will be conducted to see the benefits that can be obtained from the development of coal liquefaction with a moderate scalar type. The paramaters used as benchmarks include the NPV and IRR. In the first calculation phase, a price calculation for each operating and capital costs is calculated using coal with various water content values. After that the calculation of energy loss is 
affected by each type of water content or HHV and LHV of each coal. The amount of water content. Then form each type of coal, production risk is observed based on the mass value generated from each coal. The amount of water content value of coal which is still in the form of solid, which is operated starts from. The portential risk of

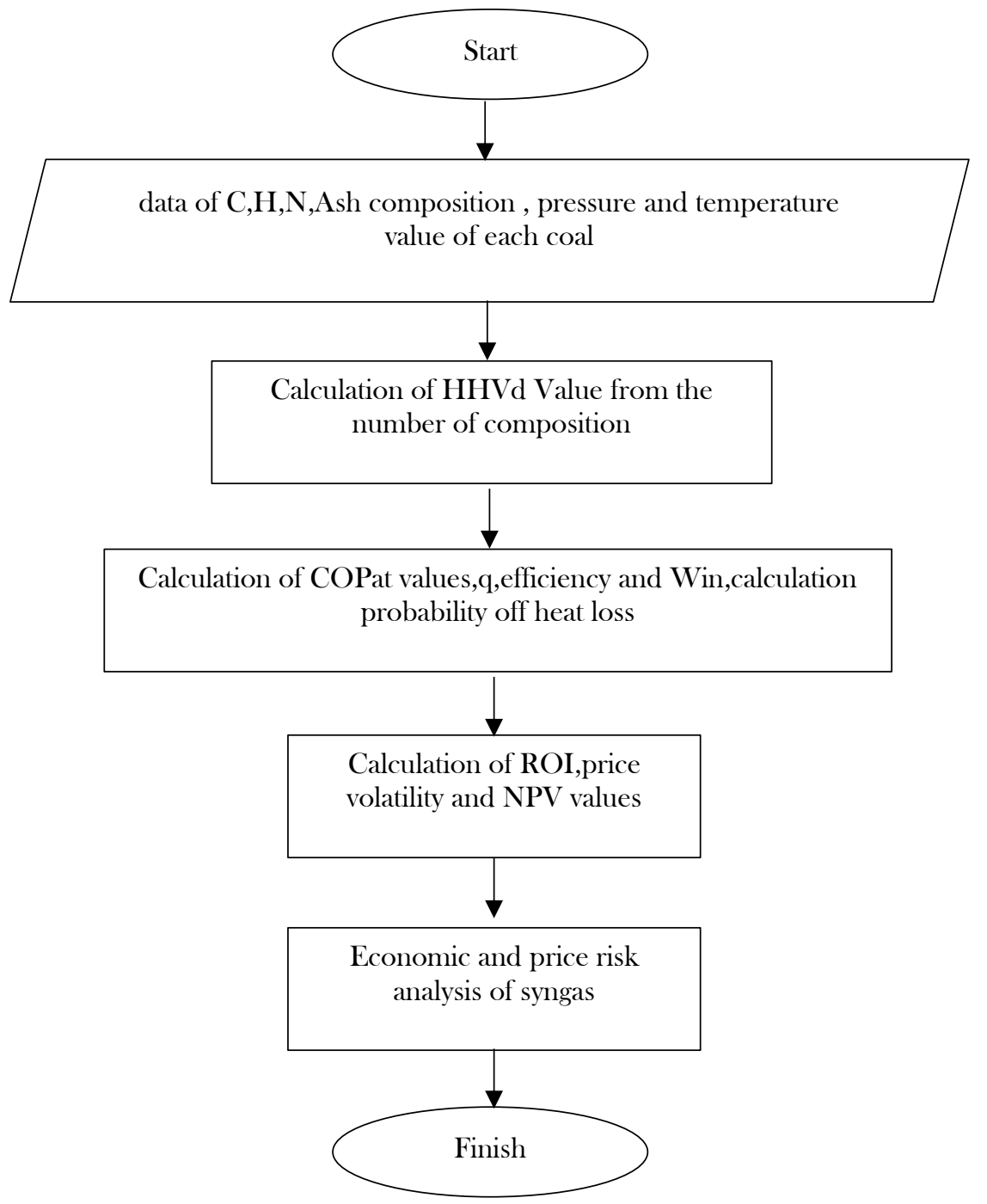

Figure 1. Flow chart of price risk analysis

each coal is determined based on the ROI ratio. Figure 1 below shows flow chart in this research.

\section{RESULTS AND DISCUSSION}

The pressure and temperature values can affect the COPat value and $\$$ space heating from the linde hampson method. Pressure and temperature sensitivity with nilai 20 bara $200 \mathrm{degC}, 30$ bara $210 \operatorname{degC}, 40$ bara $220 \mathrm{degC}$, and 50 bara $240 \operatorname{deg} \mathrm{C}$ (Table 1$)$.

The table 1 shows the results of the calculation of water content based on the Khaled method, which depends on the pressure and temperature values, the best efficiency values are at 20 coals with a temperature of $200 \mathrm{degC}$ with a COPact value of 0.096 foor the lignite type, 0.122 for the antrachite type, 0.115 for the bituminous type, and 0.106 for the subbituminous type. 


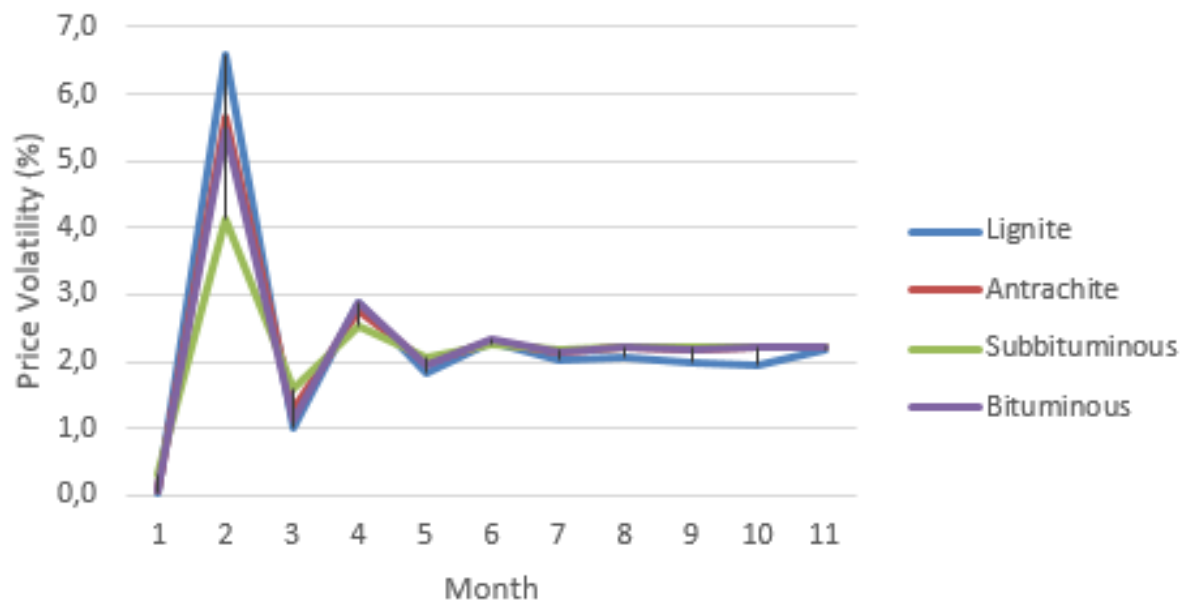

Figure 2. Annual price volatility graph

The stability of price volatility occurs in the $6^{\text {th }}$ and th months, the price volatility chart is used to see the magnitude of the risk of price changes over time. In figure 2 the $1^{\text {th }}$ and $3^{\text {rat }}$ month there was a price volatility price increase of up to $60 \%$, this shows that in the first 3 months thre was a high risk of price changes so that the stability of syngas production was neede during this time, the value of price volatility gradually stabilizd in the month $3^{\text {th }}$ to $5^{\text {th }}$ month indicating that price changes still occur but nit as high as in months 1 and 3 . Of the four types of coal, lignite has the greatest risk change to be developed, while subbituminous types have lower price risk to develop

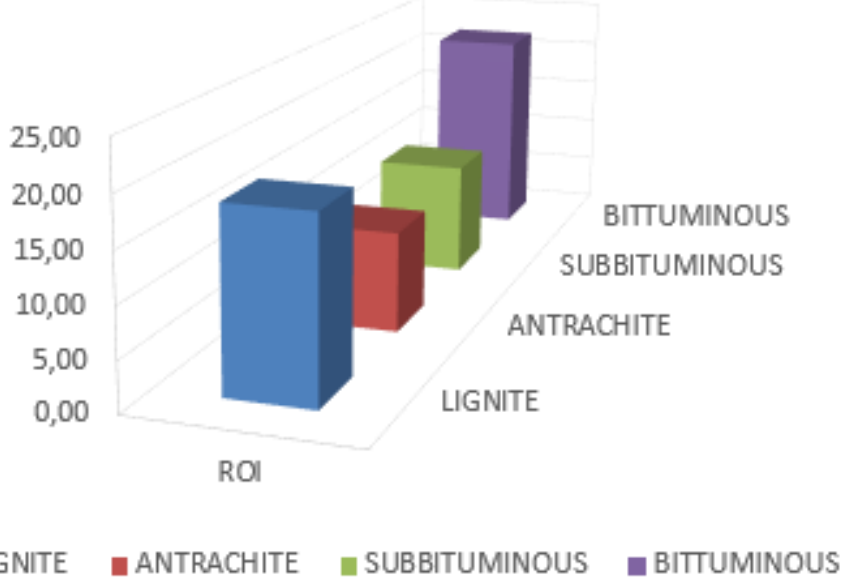

Figure 3. Return of investment

Figure 3 indicates the highest ROI (return of investment) is in the type of lignite, ROI is related efficiency which estimates the return of sales capital, namely lignite and bituminous. The ROI values is calculated based on the ratio of the investment value to net profit, from the comparison the value of lignite and bituminous has a better return of investment compared to other types 


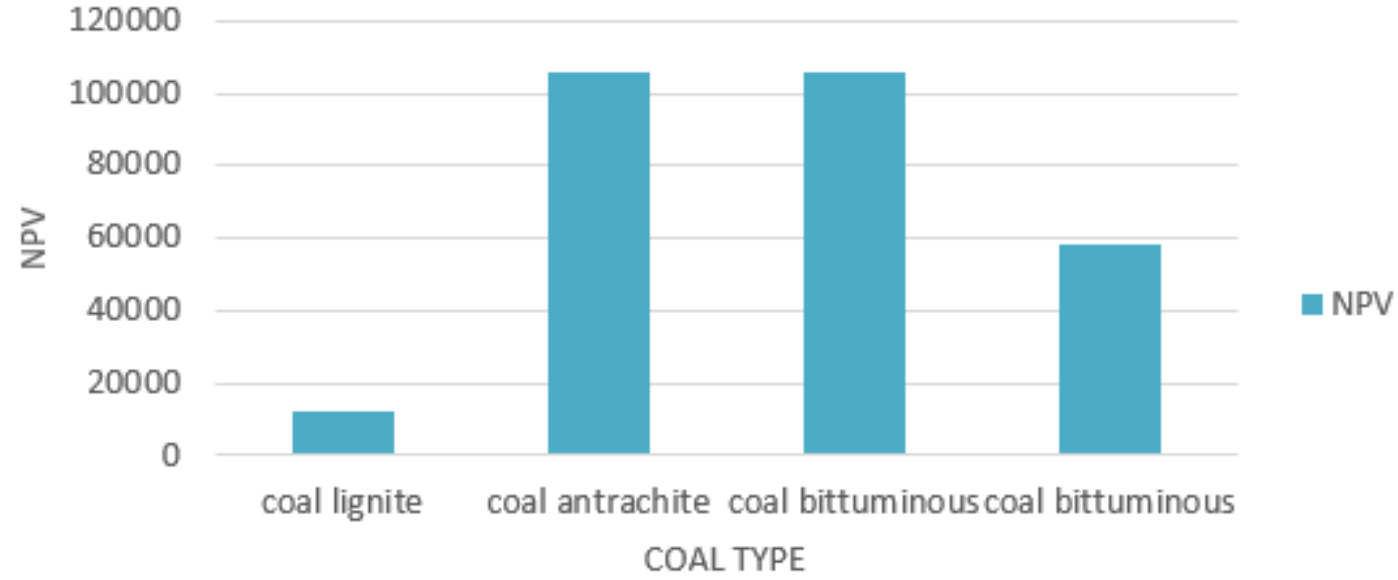

Figure 4. Net Present Value of Moderate Scalar development

It can be seen on figure 4 that coal antrachite and bituminous have a higher value.This NPV is calculated based on moderate scale development project, in which POT of each coal type is 3 years for lignite types with NPV 203012\$, 2 years for antrachite types with NPV 40256\$, 3 years for bituminous type with NPV $40256 \$$ and 4 years for subbituminous type with NPV $30084 \$$

\section{CONCLUSIONS}

1. Annual price volatility is estimated for a year, there are significant changes in the early months of the development period and then begin to stabilize in the 6 month and month of the time of development

2. Based on the price volatility value, ROI value and NPV value, a good type of coal to be developed is the bituminous type

3. NPV based on he calculation of NPV value, type of coal antrachite has a faster payback period compared to other coal types

\section{REFERENCES}

Harris, D. J., \& Roberts, D. G. (2013). Coal gasification and conversion. In The coal handbook: towards cleaner production (pp. 427-454). Elsevier.

Hubbard, W. G. (2015). Wood bioenergy. Bioenergy, 55-71. Elsevier.

Kandiyoti, R., Herod, A., Bartle, K., Morgan, T., Kandiyoti, R., Herod, A., ... Morgan, T. (2006). 5-Liquefaction: Thermal breakdown in the liquid phase. In Solid Fuels and Heavy Hydrocarbon Liquids (pp. 161-198). Elsevier Science Ltd. Oxford.

Petchers, N. (2003). Combined heating, cooling \& power handbook: technologies \& applications: an integrated approach to energy resource optimization. Fairmont Press.

Pratt, J. W. (2012). A Fischer-Tropsch synthesis reactor model framework for liquid biofuels production. SANDIA Report: SAND2012-7848.

Robinson, K. (2009). Reaction engineering of direct coal liquefaction. Energies, 2(4), 976-1006.

Wang, Q., Cui, K., Sun, T., Chen, F., \& Chen, G. (2010). Performance of a single-stage Linde-Hampson refrigerator operating with binary refrigerants at the temperature level of - 60 C. Journal of Zhejiang University SCIENCE A, 11(2), 115-127.

Yilmaz, C., Cetin, T. H., Ozturkmen, B., \& Kanoglu, M. (2019). Thermodynamic performance analysis of gas liquefaction cycles for cryogenic applications. Journal of Thermal Engineering, 5(1), 62-75. 
Table 1 The result of Space Heating Price Calculation

\begin{tabular}{|c|c|c|c|c|c|c|c|c|c|c|c|c|c|c|c|c|c|}
\hline Linde- & & \multicolumn{4}{|c|}{ Coal Lignite } & \multicolumn{4}{|c|}{ Coal Atrachite } & \multicolumn{4}{|c|}{ Coal Bituminous } & \multicolumn{4}{|c|}{ Coal Subbituminous } \\
\hline $\mathrm{P}$ & Bara & 20 & 30 & 40 & 50 & 20 & 30 & 40 & 50 & 20 & 30 & 40 & 50 & 20 & 30 & 40 & 50 \\
\hline $\mathrm{T}$ & $\operatorname{deg} \mathrm{C}$ & 200 & 210 & 220 & 240 & 200 & 210 & 220 & 240 & 200 & 210 & 220 & 240 & 200 & 210 & 220 & 240 \\
\hline$\% \mathrm{C}$ & & 65 & 65 & 65 & 65 & 93 & 93 & 93 & 93 & 78 & 78 & 78 & 78 & 72 & 72 & 72 & 72 \\
\hline$\% \mathrm{H}$ & & 4.5 & 4.5 & 4.5 & 4.5 & 2.5 & 2.5 & 2.5 & 2.5 & 5.5 & 5.5 & 5.5 & 5.5 & 5 & 5 & 5 & 5 \\
\hline $\begin{array}{l}\mathrm{y} \text { (water } \\
\text { content) }\end{array}$ & $\%$ & 0.07 & 0.07 & 0.07 & 0.06 & 0.07 & 0.07 & 0.07 & 0.06 & 0.07 & 0.07 & 0.07 & 0.06 & 0.07 & 0.07 & 0.07 & 0.06 \\
\hline COPact & & 0.096 & 0.013 & 0.007 & 0.005 & 0.122 & 0.016 & 0.009 & 0.006 & 0.115 & 0.015 & 0.008 & 0.006 & 0.106 & 0.014 & 0.008 & 0.005 \\
\hline Efficiency & $\%$ & 0.29 & 0.03 & 0.02 & 0.01 & 0.29 & 0.03 & 0.02 & 0.01 & 0.29 & 0.03 & 0.02 & 0.01 & 0.29 & 0.03 & 0.02 & 0.01 \\
\hline LHV & $\mathrm{MJ} / \mathrm{Kg}$ & 25.4 & 25.5 & 25.6 & 25.8 & 32.5 & 32.6 & 32.7 & 32.9 & 30.6 & 30.8 & 30.9 & 31.0 & 28.2 & 28.3 & 28.4 & 28.6 \\
\hline $\mathrm{Pi}$ & $\$$ & 19.51 & 19.51 & 19.51 & 19.51 & 93.17 & 93.17 & 93.17 & 93.17 & 14.29 & 14.29 & 14.29 & 14.29 & 55.6 & 55.6 & 55.6 & 55.6 \\
\hline$\$$ space & $\$$ & 1123.5 & 9454.1 & 18855.9 & 28698.8 & 5365.1 & 45147.9 & 90046.2 & 137051.0 & 822.9 & 6924.6 & 13810.9 & 21020.3 & 3201.6 & 26942.4 & 53735.9 & 81786.4 \\
\hline
\end{tabular}

